\title{
Balthasar Baro, Théâtre Complet, tome I
}

\section{Monica Pavesio}

\section{(2) OpenEdition}

\section{Journals}

\section{Edizione digitale}

URL: http://journals.openedition.org/studifrancesi/1321

DOI: 10.4000/studifrancesi.1321

ISSN: 2421-5856

\section{Editore}

Rosenberg \& Sellier

\section{Edizione cartacea}

Data di pubblicazione: 1 décembre 2015

Paginazione: 588

ISSN: 0039-2944

\section{Notizia bibliografica digitale}

Monica Pavesio, «Balthasar Baro, Théâtre Complet, tome |», Studi Francesi [Online], 177 (LIX | III) | 2015, online dal 01 décembre 2015, consultato il 11 janvier 2021. URL: http://journals.openedition.org/ studifrancesi/1321 ; DOI: https://doi.org/10.4000/studifrancesi.1321

Questo documento è stato generato automaticamente il 11 janvier 2021.

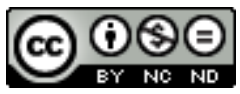

Studi Francesi è distribuita con Licenza Creative Commons Attribuzione - Non commerciale - Non opere derivate 4.0 Internazionale. 


\title{
Balthasar Baro, Théâtre Complet, tome I
}

\author{
Monica Pavesio
}




\section{NOTIZIA}

BALTHASAR BARO, Théâtre Complet, tome I, Edition de P. ESCUDÉ, P. PASQUIER, A. TEULADE, N. COURTÈs, Paris, Classiques Garnier, 2014, pp. 410.

1 Conosciuto oggi quasi unicamente dagli specialisti del teatro francese secentesco, Balthasar Baro fu, nella sua epoca, un poeta stimato e un drammaturgo di successo. Come la maggior parte degli autori suoi contemporanei, fu autore di molte pièces, ma solo dieci sono arrivate fino ai giorni nostri. Il teatro completo di Baro, diretto da B. Louvat-Molozay, riunisce queste dieci opere in tre volumi. Il primo, che qui recensiamo, contiene tre pièces: Cléosandre (1624), opera ibrida, libretto di un divertimento galante messo in scena a Toulouse nello stesso anno, scritto in francese e in occitano, ma anche narrazione dei quattro giorni della festa del Carnevale; Saint Eustache martyr (1649) poema drammatico agiografico, Cariste (1651), tragicommedia atipica. Queste opere, molto diverse tra loro, sono rappresentative dell'estetica di Baro e delle tendenze principali del teatro barocco dell'epoca. Come affermano P. Pasquier e B. LouvatMolozay nell'introduzione generale, il drammaturgo si appropria degli stereotipi appartenenti ai diversi generi, per creare opere convenzionali, ma nello stesso tempo molto originali, che devono essere riscoperte.

2 Dopo l'introduzione di P. Pasquier e B. Louvat-Molozay, il volume contiene le tre pièces modernizzate e annotate dai rispettivi curatori (P. Escudé per Cléosandre; A. Teulade e P. Pasquier per Saint Eustache martyr; N. Courtès, per Cariste), precedute da ampie introduzioni, una bibliografia e un indice dei nomi. I due volumi, previsti per il 2015 e il 2016, conterranno rispettivamente Célinde, Clorise e Parthénie e Le Prince fugitif, Clarimonde, Rosemonde e L'Amante vindicative. 